\title{
Platinum nanoparticles inhibit intracellular ROS generation and protect against Cold Atmospheric Plasma-induced cytotoxicity
}

\author{
Sebnem Gunes ${ }^{1,2,3}$, Zhonglei He ${ }^{1,2,3}$, Renee Malone ${ }^{1}$, Patrick J Cullen ${ }^{1,4}$, James F Curtin ${ }^{1,2,3}$
}

${ }^{1}$ BioPlasma Research Group, School of Food Science and Environmental Health, Technological University

Dublin, Dublin, Ireland; ${ }^{2}$ Nanolab, FOCAS Research Institute, Technological University Dublin, Dublin, Ireland; and ${ }^{3}$ Environmental, Sustainability and Health Research Institutes, Technological University Dublin, Dublin, Ireland; ${ }^{4}$ School of Chemical and Biomolecular Engineering, University of Sydney, Australia

\section{Email address of each author:}

Sebnem Gunes: sebnem.gunes@tudublin.ie

Dr. Zhonglei He: zhonglei.he@tudublin.ie

Dr. Renee Malone: renee.malone@tudublin.ie

Prof. Patrick J Cullen: patrick.cullen@sydney.edu.au

Prof. James F Curtin: james.curtin@tudublin.ie

\section{Corresponding author}

James Curtin (james.curtin@tudublin.ie)

Postal address: Technological University Dublin, Dublin 1, Ireland

Business Phone number: +353-1-402-4408

Home Phone number: +353-1-402-4408

Fax number: +353-1-402-4408 


\section{Graphical Abstract}

PtNPs are potent catalase and superoxide dismutase mimetics which makes them strong antioxidant candidates for the protection of cells against oxidative stress. CAP was generated using a Dielectric Barrier Device (DBD) system with a voltage output of $75 \mathrm{kV}$ at a frequency of $50 \mathrm{~Hz}$. A range of concentrations of 3nm uncoated PtNPs combined with CAP were examined in human U-251 MG Glioblastoma (GBM) cells and non-cancerous human embryonic kidney HEK293 cells. The protective effects of PtNPs against CAP were explored using several biochemical indicators of oxidative stress and cytotoxicity.

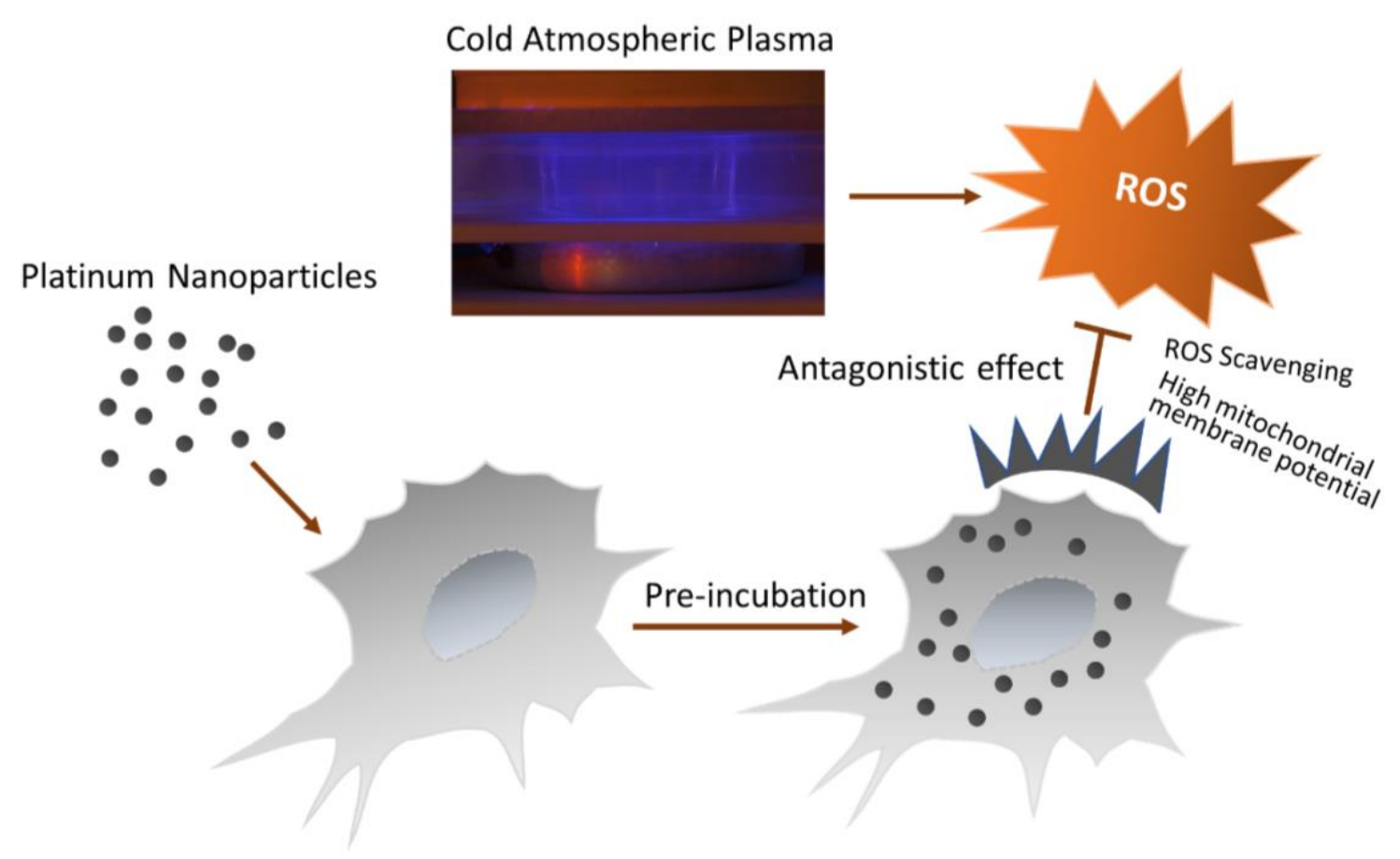




\section{Abstract}

Platinum nanoparticles (PtNPs) have been investigated for their antioxidant abilities in a range of biological and other applications. The ability to reduce off-target CAP cytotoxicity would be useful in Plasma Medicine, however, little has been published to date about the ability of PtNPs to reduce or inhibit the effects of CAP. Here we investigate whether PtNPs can protect against CAP-induced cytotoxicity in cancerous and non-cancerous cell lines. PtNPs were shown to dramatically reduce intracellular reactive species (RONS) production in human U-251 MG cells. However, RONS generation was unaffected by PtNPS in medium without cells. PtNPs protect against CAP induced mitochondrial membrane depolarization, but not cell membrane permeabilization which is a CAP-induced RONS-independent event. PtNPs act as potent intracellular scavengers of reactive species and can protect both cancerous U-251 MG cells and non-cancerous HEK293 cells against CAP induced cytotoxicity. PtNPs may be useful as a catalytic antioxidant for healthy tissue and for protecting against CAP-induced tissue damage.

\section{Keywords}

Cold Atmospheric Plasma, Free Radicals, Platinum Nanoparticles, Antioxidants, Cancer Treatment, Nanotherapy 


\section{Background}

Cold atmospheric plasma (CAP), also known as non-thermal atmospheric plasma (NTAP), has emerged as a promising technique for biomedical applications, including sterilization, wound healing and cancer therapy ${ }^{1,2}$. CAP is known to generate bioactive short- and long-lived reactive oxygen species (ROS) and reactive nitrogen species (RNS), as well as a unique physical environment, including heat generation, pressure gradients, electrostatic and electromagnetic fields ${ }^{3,4}$. In many types of tumours, cancer cells have been found to possess a higher intracellular ROS level compared to normal cells, due to their more rapid proliferation and higher, altered metabolic activities ${ }^{5}$. Therefore, the antioxidant system in cancer cells is under a heavier workload, potentially causing a higher sensitivity of cancer cells to oxidative stress compared to normal cells, which can be targeted for the development of specific therapies. For example, several anticancer drugs, such as imexone ${ }^{6}$, motexafin gadolinium ${ }^{7}$ and nitric oxide-donating aspirin ${ }^{8}$, have been developed to increase ROS level in cancer cells beyond their tolerable allowance to trigger cell death. CAP has been demonstrated to have selectively anti-tumour effects against many cancer cell lines ${ }^{9,10}$. However, even with non-immediate damage to healthy tissues by precise CAP treatment, the increase of the ROS levels in surrounding tissues may induce DNA damage and cause secondary malignancies, which can be a potential side effect induced by $\mathrm{CAP}^{10,11}$.

Recently, it has been demonstrated that CAP treatment has synergistic anti-cancer effects in combination with various nanoparticles, including gold nanoparticles ${ }^{12}$, silver nanoparticles ${ }^{13}$, iron nanoparticles ${ }^{14}$ and iron oxide-based magnetic nanoparticles ${ }^{15}$.

Antioxidants protect against cancer occurrence and cardiovascular diseases ${ }^{16,17}$ by scavenging ROS. However, antioxidants as a redox agent may also promote free radicals and secondary ROS and the excess amount of these increases the cancer risk ${ }^{18,19}$. Unlike platinum-based compounds, such as cisplatin that are cytotoxic agents ${ }^{20,21}$, PtNPs display promising antioxidant activity, functioning as superoxide dismutase 
(SOD)/catalase mimetics 22,23 and catalyse the decomposition of $\mathrm{H}_{2} \mathrm{O}_{2}{ }^{24,25}$ and $\mathrm{ROS}^{26} \cdot \mathrm{H}_{2} \mathrm{O}_{2}$ is a long-lived reactive species. In cells it can interact with DNA and other biomolecules and can cause biomacromolecular damage 27,28 . Therefore, controlling and removal of excess $\mathrm{H}_{2} \mathrm{O}_{2}$ in neighbouring healthy tissues will improve the selectivity of CAP as a treatment for cancer.

Many previous in vivo and in vitro studies proposed that coated or uncoated PtNPs have negligible cytotoxic effects with cell compatible materials ${ }^{29-31}$. PtNPs are capable of scavenging ROS and show SOD catalytic activity ${ }^{26,32,33}$. PtNPs scavenge $\mathrm{O}_{2}^{-}$(superoxide anion radicals) and $\cdot \mathrm{OH}$ (hydroxyl radicals) acting as antioxidants ${ }^{30,33}$. It has been reported that PtNPs reduce oxidative stress-mediated cell damage and cell death $^{34,35}$. Therefore, they may act as an antioxidant against CAP treatment. However, due to the wide range of CAP devices and types, the variety of cell types, different sizes, shapes, purity, and coating of PtNP and variability of experimental conditions, the detailed mechanism needs further research.

In this study, we determined the effects of PtNPs combined with CAP in U-251 MG and HEK293 cells. We demonstrate that PtNPs act as intracellular ROS generation scavengers and protect against CAP-induced cytotoxicity. PtNPs may be useful as a catalytic antioxidant for healthy tissue and protect against CAPinduced tissue damage. Our results indicate that PtNP could be developed as a safe method to reduce the side effects and potential risks of CAP and other ROS-related therapies on adjacent healthy tissues during treatment.

\section{Methods}

\section{Cell Culture}

The human brain glioblastoma cancer cell line (U-251 MG) was obtained from Dr Michael Carty (Trinity College Dublin) and the human embryonic kidney cell line (HEK293) from Dr Darren Fayne (Trinity College Dublin). Cells were cultured in Dulbecco's Modified Eagle's Medium-high glucose (Merck) supplemented 
with $10 \%$ fetal bovine serum (Merck) and $1 \%$ penicillin (Thermo Fisher Scientific) and maintained in a humidified incubator containing $5 \%(\mathrm{v} / \mathrm{v}) \mathrm{CO}_{2}$ atmosphere at $37^{\circ} \mathrm{C}$ in $\mathrm{TC}$ flask $\mathrm{T} 25$, standard for adherent cells (Sarstedt). Culture medium was changed every 2-3 days upon reaching around $80 \%$ confluence. Cells were routinely sub-cultured in new flasks using a $0.25 \%$ Trypsin-EDTA solution (Merck). Platinum, nanoparticle dispersion, $3 \mathrm{~nm}$, was purchased from Merck.

\section{Alamar blue cell viability assay}

Cell viability was analysed using the Alamar blue assay (Thermo Fisher Scientific). U-251 MG and HEK293 cells were seeded at a density of $1 \times 10^{4}$ cells/well (100 $\mu$ l culture medium per well) into 96-well plates (Sarstedt) and were incubated overnight. Medium was removed and fresh culture medium containing 0$100 \mu \mathrm{g} / \mathrm{ml}$ PtNPs was added and incubated overnight. Medium was removed for DBD (DIT-120 plasma device) CAP (75 kV, $50 \mathrm{~s})$ treatment at $70-80 \%$ confluences and fresh culture medium was replaced immediately following CAP treatment. Following a $24 \mathrm{~h}$ incubation at $37^{\circ} \mathrm{C}$, the cells were rinsed once with phosphate buffered saline (Merck), incubated for $3 \mathrm{~h}$ with $10 \%$ Alamar blue in culture medium solution. As a second method, we treated U-251 MG cells with PtNPs immediately prior to CAP treatment. An Alamar Blue cell viability assay was performed 48 hours after CAP treatment. Fluorescence was measured (excitation, $530 \mathrm{~nm}$; emission, $595 \mathrm{~nm}$ ) by a Victor $3 \mathrm{~V} 1420$ microplate reader (Perkin Elmer).

\section{Measurement of ROS induced by CAP}

Reactive oxygen species generation induced by CAP were detected using a cell permeable oxidant sensitive fluorescent dye 2,7-dichlorodihydrofluorescein diacetate $\left(\mathrm{H}_{2} \mathrm{DCFDA}\right)$ (Thermo Fisher Scientific). U-251 MG cells were seeded in $35 \times 10 \mathrm{~mm}$ Petri dishes (Sarstedt) at a density of $1 \times 10^{5} \mathrm{cells} / \mathrm{ml}$. After $24 \mathrm{~h}$, growth medium was removed and PtNPs $(5 \mu \mathrm{g} / \mathrm{ml}$ and $0.032 \mu \mathrm{g} / \mathrm{ml}$ ) in medium were added and then incubated overnight. Culture medium was replaced with fresh serum-free medium containing $25 \mu \mathrm{M}$ $\mathrm{H}_{2}$ DCFDA and cells were incubated for $30 \mathrm{~min}$ at $37^{\circ} \mathrm{C}$. Cells were washed with fresh medium once and 
then with PBS twice, and then treated with CAP at $75 \mathrm{kV}$ for $50 \mathrm{~s}$. Following CAP treatment, cells were incubated with fresh medium for 10 minutes at $37{ }^{\circ} \mathrm{C}$ before cell harvesting. To prepare aliquots, all floating and attached cells were collected by trypsinisation. All liquids, including medium, washing PBS and trypsin-cell suspension, were transferred into one tube and centrifuged at $1200 \mathrm{rpm}$ for $5 \mathrm{~min}$. Cells were resuspended in PBS and BD Accuri ${ }^{\mathrm{TM}}$ C6 Plus flow cytometry (BD Bioscience) was used to detect and measure fluorescence. Flow analysis was carried out with a $488 \mathrm{~nm}$ laser for excitation and FL1 standard filter for $\mathrm{H}_{2}$ DCFDA measurement.

\section{Detection of cell membrane damage}

Viable and dead cells were recorded using Propidium lodide (PI) staining (Merck). U-251 MG cells were plated in $35 \times 10 \mathrm{~mm}$ Petri dishes (Sarstedt) at a density of $1 \times 10^{5}$ cells $/ \mathrm{ml}$. After $24 \mathrm{~h}$, growth medium was removed and PtNPs $(5 \mu \mathrm{g} / \mathrm{ml}$ and $0.032 \mu \mathrm{g} / \mathrm{ml})$ in medium were added and incubated for a further $24 \mathrm{~h}$. Medium was removed and cells were treated directly to CAP $75 \mathrm{kV}$ for $50 \mathrm{~s}$ and, $24 \mathrm{~h}$ after CAP treatment, cells were collected by trypsinization, and pelleted by centrifugation at $1200 \mathrm{rpm}$ for 5 minutes. The pellet was resuspended in $0.5 \mathrm{ml}$ PBS and cells were stained with $0.4 \mu \mathrm{g} / \mathrm{ml} \mathrm{PI}$ for 5 minutes. The fluorescence of PI was then measured using BD Accuri ${ }^{\mathrm{TM}}$ C6 Plus flow cytometry at FL2 $(585 / 40 \mathrm{~nm})$ standard filter.

\section{Measurement of mitochondrial membrane potential}

Dual-emission potential-sensitive fluorescence dye JC-1 (Merck) was used to measure mitochondrial membrane potential of cells following CAP treatment. U-251 MG cells were seeded in $35 \times 10 \mathrm{~mm}$ Petri dishes (Sarstedt) at a density of $1 \times 10^{5}$ cells $/ \mathrm{ml}$. After $24 \mathrm{~h}$, growth medium was replaced with PtNPs (5 $\mu \mathrm{g} / \mathrm{ml}$ and $0.032 \mu \mathrm{g} / \mathrm{ml}$ ) in medium and incubated for a further $24 \mathrm{~h}$. Medium was removed, and the cells were exposed to CAP directly at $75 \mathrm{kV}$ for $50 \mathrm{~s}$. Following CAP treatment, cells were incubated with fresh medium overnight at $37^{\circ} \mathrm{C}$. Medium was removed and $2.5 \mu \mathrm{g} / \mathrm{ml} \mathrm{JC}-1$ in medium was added to cells. After 10-minute incubation time at room temperature and absence of light, cells were washed with PBS twice 
and all cells were collected by trypsinization and centrifugation at $1200 \mathrm{rpm}$ for $5 \mathrm{~min}$. The supernatant was removed, and cells were resuspended in $0.3 \mathrm{ml}$ PBS for flow cytometry (BD Bioscience) analysis. Fluorescence intensity was measured using the FL1 $(530 \mathrm{~nm})$ and FL2 $(585 \mathrm{~nm})$ channels with emission spectral overlap compensation (7\% FL1/FL2 and 13\% FL2/ FL1).

\section{Statistical Analysis}

Independent experiments were carried out for each data point in triplicate. Prism 6 (GraphPad Software) was used to carry out curve fit and statistical analysis. Data is shown as the $\%$ and error bars of all figures are presented using the standard error of the mean (S.E.M). Two-tailed P values were used and the Alpha for all experiments is 0.05 . Data points were verified using one-way ANOVA and Tukey's multiple comparison post-test to determine the significance, as indicated in figures $\left({ }^{*} \mathrm{P}<0.05, * * \mathrm{P}<0.01\right.$, $* * * \mathrm{P}<0.001, * * * * \mathrm{P}<0.0001)$.

\section{Results}

\section{CAP-induced antagonistic cytotoxicity of PtNPs on cancer cells}

We wished to determine whether PtNP could have a protective effect against CAP-induced cytotoxicity. Dose response curves were established using a range of concentrations (Figure $1 \mathrm{~A}, \mathrm{~B}$ ) to determine the appropriate nontoxic concentrations of PtNPs in cells with the combination of CAP. Control cells were treated with a range of concentrations of PtNPs in the absence of CAP. An Alamar Blue cell viability assay was performed to determine the extent of cytotoxicity. Approximately $50 \%$ loss of cell viability was observed $24 \mathrm{~h}$ after U-251 MG cells were exposed to $50 \mathrm{~s}$ CAP treatment. As Figure $1 \mathrm{~A}$ and $1 \mathrm{~B}$ demonstrate, lower concentrations of PtNPs alone did not cause any toxicity to cells without CAP treatment. Moreover, protection from CAP-induced cytotoxicity was observed when pre-incubated with PtNPs. Compared with CAP only, the significant protective concentrations of PtNP ranged from $4 \mu \mathrm{g} / \mathrm{ml}$ 
bioRxiv preprint doi: https://doi.org/10.1101/2021.02.18.431888; this version posted February 18,2021 . The copyright holder for this preprint (which was not certified by peer review) is the author/funder, who has granted bioRxiv a license to display the preprint in perpetuity. It is made available under aCC-BY 4.0 International license.

to $0.0512 \mathrm{ng} / \mathrm{ml}$ when PtNP were preincubated for $24 \mathrm{~h}$ (Figure $1 \mathrm{~A}$ ) and from $4 \mathrm{\mu g} / \mathrm{ml}$ to $0.256 \mathrm{ng} / \mathrm{ml}$ when PtNP were added immediately prior to CAP treatment (Figure 1B). As seen from the dose response curves in Supplementary Figure S1a The IC 50 value of PtNP alone is $8.091 \mu \mathrm{g} / \mathrm{ml}(95 \%$ confident intervals $=6.408$ $\mu \mathrm{g} / \mathrm{ml}$ to $10.22 \mu \mathrm{g} / \mathrm{ml})$. The $\mathrm{IC}_{50}$ value of PtNP in combination with $50 \mathrm{~s}$ CAP treatment is $8.03 \mu \mathrm{g} / \mathrm{ml}(95 \%$ confident intervals $=5.663 \mu \mathrm{g} / \mathrm{ml}$ to $11.39 \mu \mathrm{g} / \mathrm{ml}$ ). Based on the pre-incubation data, $0.032 \mu \mathrm{g} / \mathrm{ml}$ of PtNPs was selected as a protective concentration and $5 \mu \mathrm{g} / \mathrm{ml}$ of PtNPs to compare with $0.032 \mu \mathrm{g} / \mathrm{ml}$ for the cytotoxicity and protective effects for all future experiments. All cell viability data are normalized relative to control cells.

Note that this demonstrates that CAP and PtNPs have an antagonistic cytotoxicity to U-251 MG cancer cell lines.

A

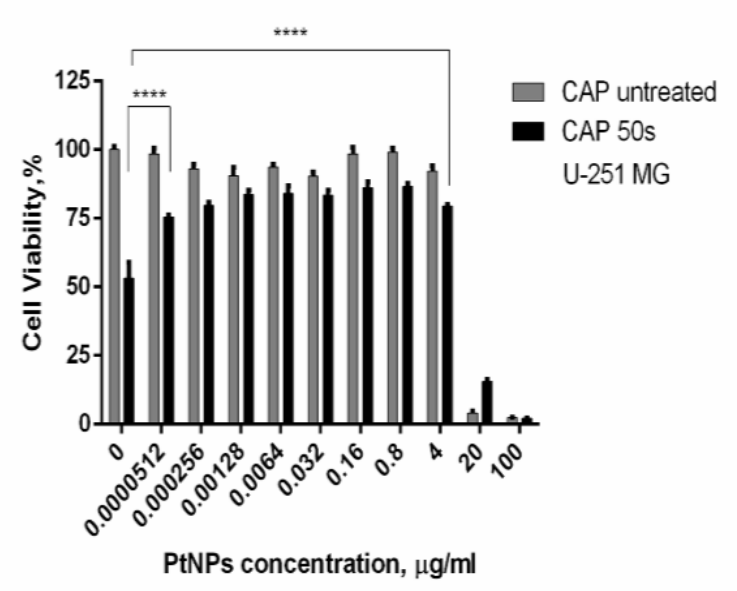

B

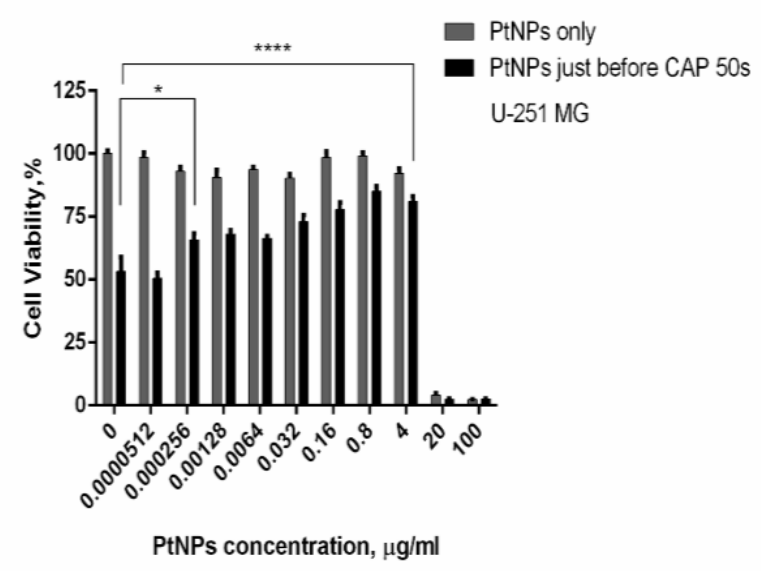

Figure 1. Dose responses for PtNPs treatment. (A) U-251 MG cells were incubated with increasing concentrations $(0 \leq 100 \mu \mathrm{g} / \mathrm{ml}$ ) of PtNPs for 24h before CAP treatment and Alamar blue analysis was carried out $24 \mathrm{~h}$ after CAP treatment (B) U-251 MG cells were treated with corresponding amounts of PtNPs immediately before CAP treatment and Alamar blue cell viability assay was carried out $48 \mathrm{~h}$ after CAP treatment. 


\section{Reactive Oxygen Species (ROS) Scavenging Activity of PtNPs in U-251 MG cells}

To determine the effects of PtNP on ROS generation by CAP, U-251 MG cells were preloaded with $\mathrm{H}_{2}$ DCFDA. ROS levels in cells following CAP treatment significantly increased compared to the negative control (Figure $2 \mathrm{~A})\left({ }^{* * * *} \mathrm{P}<0.0001\right)$. The levels of intracellular oxidised $\mathrm{H}_{2} \mathrm{DCFDA}$ were decreased when cells were pre-incubated with three different non-toxic concentrations of PtNPs; $0.0512 \mathrm{ng} / \mathrm{ml}, 0.032$ $\mu \mathrm{g} / \mathrm{ml}$, and $5 \mu \mathrm{g} / \mathrm{ml}$ as seen in Figure 2B. The mean fluorescence levels of CAP-treated cells pre-incubated with PtNPs were decreased by a factor of 1.5, 3, and 2.6 times, respectively, compared to CAP-treated cells in the absence of PtNPs (****P $<0.0001)$.

A

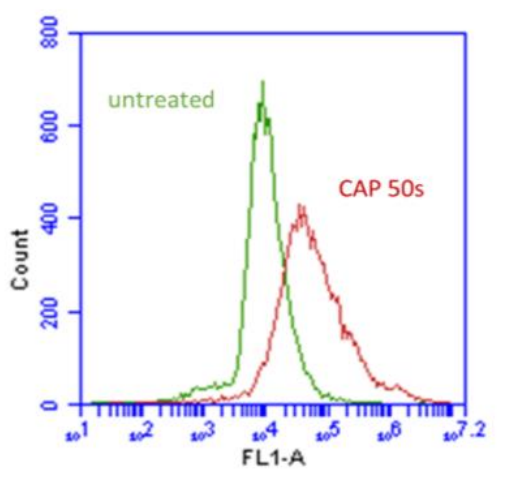

C

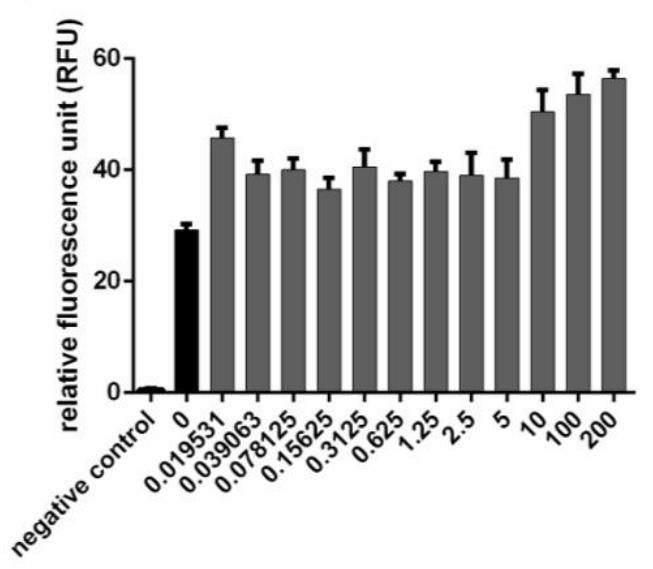

PtNPs concentration, $\mu \mathrm{g} / \mathrm{ml}$
B

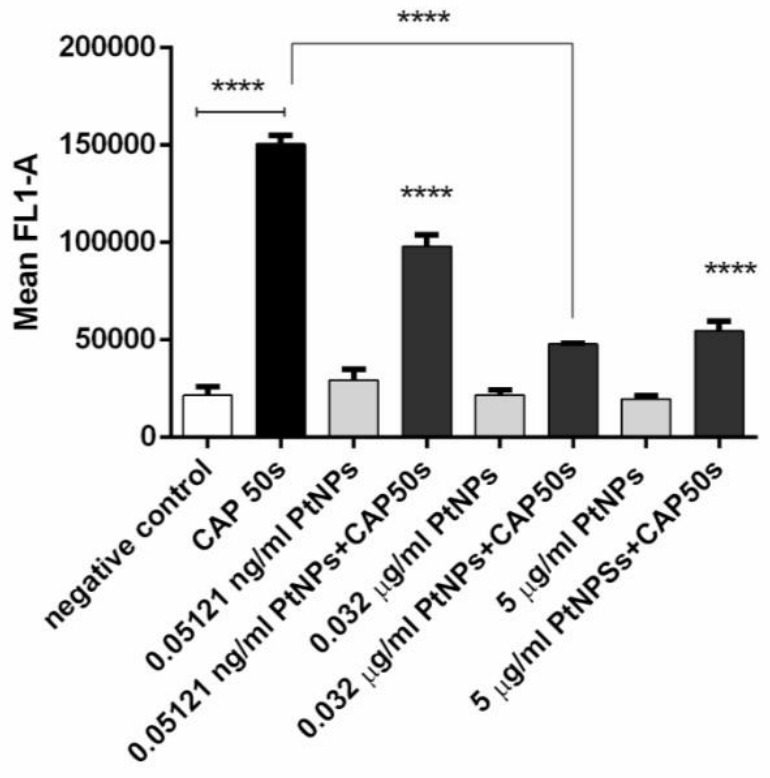

Figure 2. Antioxidant activity. (A) Comparison of ROS production in U-251 MG cells with CAP treatment and untreated control (B) Negative Control (empty column) represents untreated cells, black CAP treatment and 
others 3 different concentrations of PtNPs $(0.05121 \mathrm{ng} / \mathrm{ml} ; 0.032 \mu \mathrm{g} / \mathrm{ml}, 5 \mu \mathrm{g} / \mathrm{ml})$ with and without CAP treatment and data was acquired by flow cytometry. (C) Fluorescence level of oxidised $\mathrm{H}_{2}$ DCFDA was measured in medium without cells after CAP treatment with increasing concentrations $(0 \leq 200 \mu \mathrm{g} / \mathrm{ml}$ ) of PtNPs. Data retrieved from the Perkin Elmer microplate reader measures the fluorescence in each well of the microplate and generates readings as arbitrary fluorescent unit values.

In contrast, the presence of PtNPs in culture media only (without cells) was not sufficient to prevent oxidation of $\mathrm{H}_{2}$ DCFDA in response to 50s CAP treatment suggesting that either localized accumulation and concentration of PtNP, or a role for the intracellular redox machinery, are important for the antioxidant properties displayed (Figure $2 \mathrm{C}$ ).

\section{Effect of PtNPs combined with CAP on cell membrane damage}

We have previously demonstrated that exposure of U-251 MG cells to CAP DBD induces rapid membrane damage and permeability to dyes such as Propidium lodide (PI) ${ }^{36}$. To assess the effect of PtNP on membrane damage, U-251 MG cells were stained with PI. PtNPs alone were not observed to cause membrane damage (Figure 3). As expected, a rapid increase in membrane permeability was observed following exposure to CAP. The mean fluorescence in cells with $5 \mu \mathrm{g} / \mathrm{ml}$ PtNPs exposed to the CAP increased by a factor of 1.5 , while concentrations of PtNPs $0.032 \mu \mathrm{g} / \mathrm{ml}$ combined by CAP showed no a significant difference, compared to cells following only the CAP treatment. As seen Figure $3 \mathrm{~A}$, untreated cells when compared to CAP only and PtNPs combined with CAP showed significant difference $(* * P<0.01$, $* * * * \mathrm{P}<0.0001)$. The percentage of viable and dead cells did not show significant difference after PI staining between pre-incubation of PtNPs combined with CAP treatment and CAP 50 s treatment only (Figure 3B). Figure 3C illustrates the emitting fluorescence from viable and dead cells. This observation suggests 50 s CAP by the DBD device induces immediate membrane permeabilization accounting for a fraction of the overall cytotoxicity that is not prevented by the presence of PtNPs. 
A

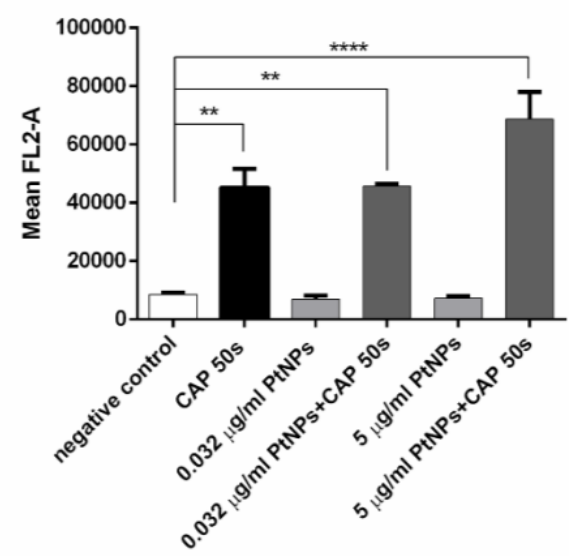

B

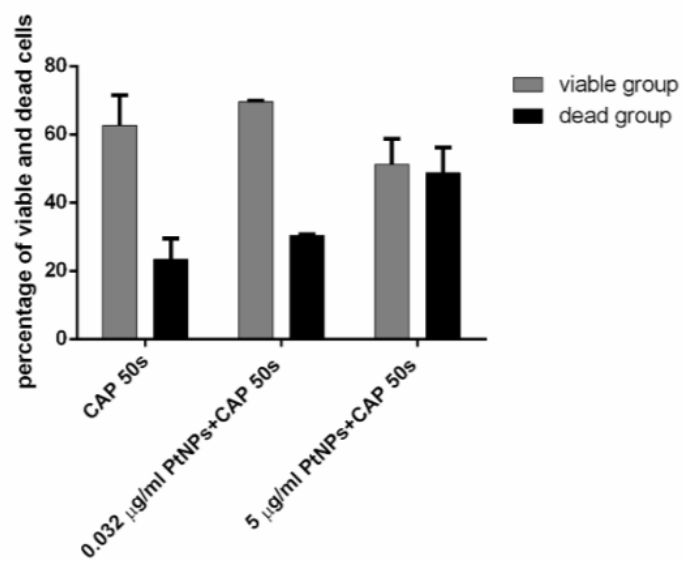

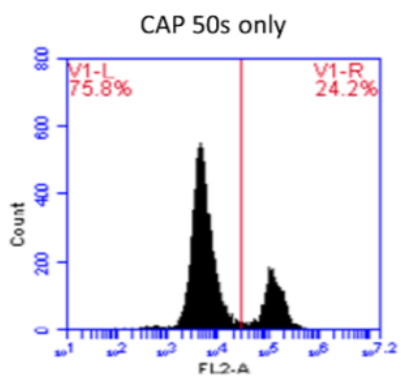

$0.032 \mu \mathrm{g} / \mathrm{ml}$ PtNPs + CAP $50 \mathrm{~s}$

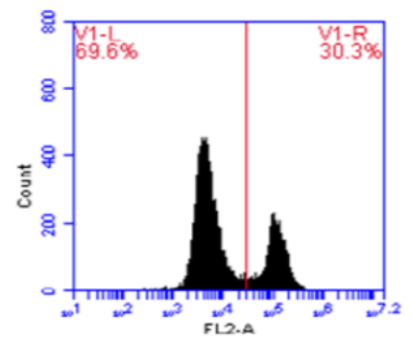

$5 \mu \mathrm{g} / \mathrm{ml}$ PtNPs + CAP $50 \mathrm{~s}$

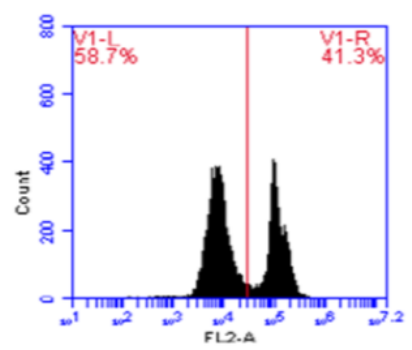

Figure 3. Cell membrane damage. (A) Fluorescence level of PI staining in untreated, CAP-treated, with preincubated $0.032 \mu \mathrm{g} / \mathrm{ml}$ and $5 \mu \mathrm{g} / \mathrm{ml}$ of PtNPs alone and the combination of PtNPs and CAP-treated cells. (B) Comparison of the percentage of viable and dead cells with CAP treatment only and $0.032 \mu \mathrm{g} / \mathrm{ml}$ and $5 \mu \mathrm{g} / \mathrm{ml}$ of PtNPs combined with CAP. (C) The percentage of viable, on the left side, and dead, on the right side, cells emitting red fluorescence. Figures represent CAP treatment only, $0.032 \mu \mathrm{g} / \mathrm{ml}$ of PtNPs combined with CAP and $5 \mu \mathrm{g} / \mathrm{ml}$ of PtNPs combined with CAP.

\section{High mitochondrial membrane potential with PtNPs combined by CAP}

Inhibition of ROS generation in cells, but no effect on the immediate membrane damage induced by CAP, suggests that PtNPs play a protective role by modifying the intracellular ROS signaling in cells following exposure to CAP and membrane damage. Mitochondria play an important role in ROS-mediated cell death by both producing and augmenting cellular responses to reactive species. The accumulation of ROS in cells can result in oxidative stress which leads to mitochondrial dysfunction and CAP is known to cause the loss of the mitochondrial membrane potential $(\Delta \psi \mathrm{m})^{37}$.

We therefore investigated whether PtNP affected mitochondrial membrane depolarization. U-251 MG 
cells were stained with JC- 1 . The dimeric form of JC-1 predominates in healthy mitochondria and exhibits a red fluorescence (Figure 4). In contrast, mitochondrial membrane depolarization following CAP treatment led to a shift to green fluorescence indicating that JC-1 was predominantly monomeric. To determine the changes of JC-1 monomer/dimer mean fluorescence ratio in U-251 MG cells, PtNPs concentrations of $0.032 \mu \mathrm{g} / \mathrm{ml}$ and $5 \mu \mathrm{g} / \mathrm{ml}$ with and without $50 \mathrm{~s}$ CAP treatment were evaluated. As evident in Figure 4, a low ratio of monomers-to-aggregates was observed in PtNPs treated cells, further indicating that the concentrations of PtNP selected did not have a toxic effect on cells. CAP treatment led to the expected increment of the green/red fluorescence ratio, with a threefold increase in mean fluorescence intensity compared to untreated controls.

A

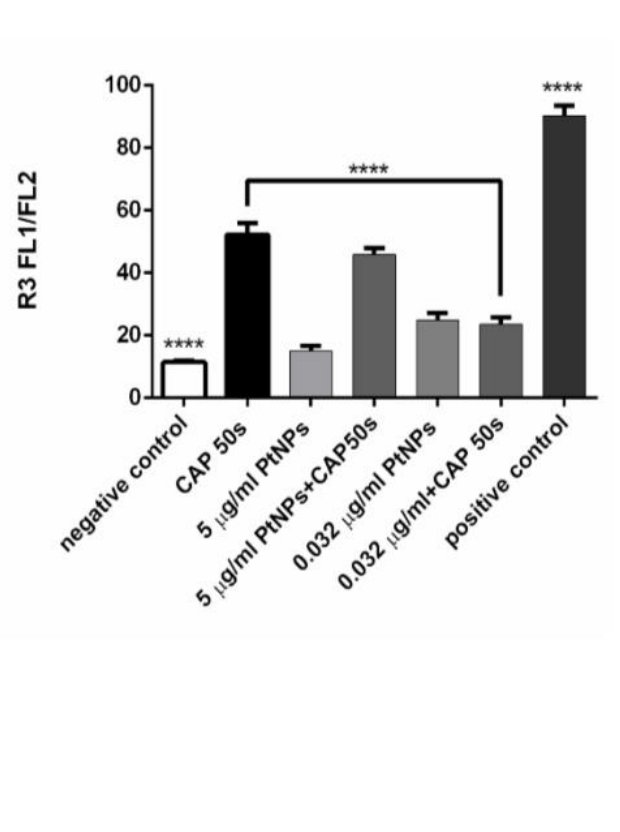

B
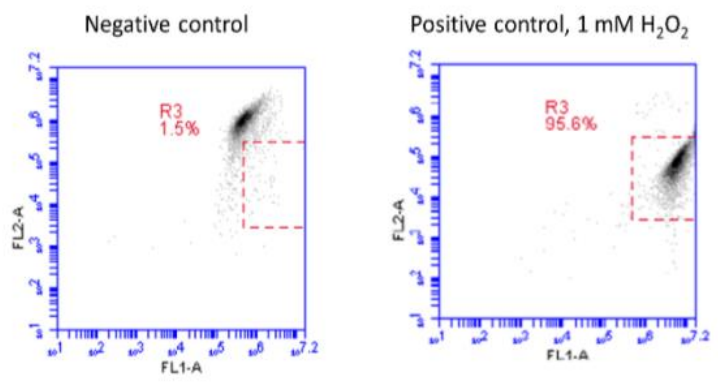

CAP 50s only

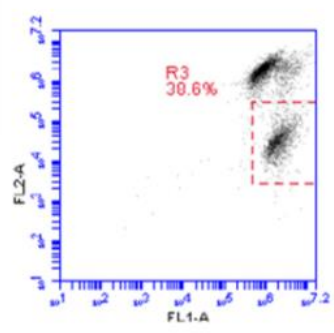

$0.032 \mu \mathrm{g} / \mathrm{ml}$ PtNPs + CAP $50 \mathrm{~s}$

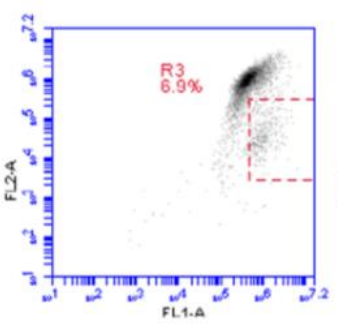

$5 \mu \mathrm{g} / \mathrm{ml}$ PtNPs + CAP $50 \mathrm{~s}$

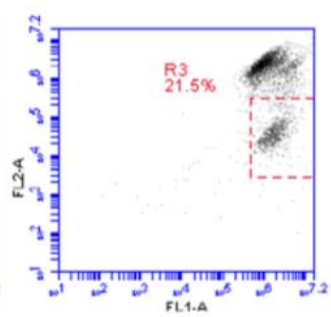

Figure 4. Mitochondrial membrane depolarisation in GBM. (A) Cells emitting green fluorescence and with low mitochondrial membrane potential against cells emitting red fluorescence and with high mitochondrial membrane potential are represented as a bar graph and mean fluorescence ratio of FL1/FL2 was acquired from the gate R3 in panel (B). Bars represent untreated, $0.032 \mu \mathrm{g} / \mathrm{ml}$ and $5 \mu \mathrm{g} / \mathrm{ml}$ of PtNPs combined with and without CAP, CAP treatment alone and $1 \mathrm{mM} \mathrm{H}_{2} \mathrm{O}_{2}$ as positive control groups toxicity comparison. (B) Cells emitting green fluorescence and with low mitochondrial membrane potential are shown in percentage as R3. Figures represent negative control, positive control, CAP treatment only, $0.032 \mu \mathrm{g} / \mathrm{ml}$ of PtNPs combined with CAP and $5 \mu \mathrm{g} / \mathrm{ml}$ of PtNPs combined with CAP. 
These results indicate that the $\Delta \Psi \mathrm{m}$ is disrupted by CAP treatment and JC-1 remained in its monomeric form. The extent of membrane depolarization by CAP was similar to that observed when cells are exposed to $1 \mathrm{mM} \mathrm{H}_{2} \mathrm{O}_{2}$ treatment as a positive control group. Interestingly, the ratio of FL1/FL2 mean fluorescence intensity in cells with PtNPs that are exposed to the CAP treatment for $50 \mathrm{~s}$ decreases by a factor of 2.5 and 1.3 with $0.032 \mu \mathrm{g} / \mathrm{ml}$ and $5 \mu \mathrm{g} / \mathrm{ml}$ of PtNPs, respectively, compared to $50 \mathrm{~s}$ CAP treatment alone (****P $<0.0001$ ). This observation shows that PtNPs, especially at a concentration of $0.032 \mu \mathrm{g} / \mathrm{ml}$, support a high retention of mitochondrial membrane potential by removing the disrupting effect of the CAP treatment; therefore, JC-1 moves and aggregates inside the mitochondria.

\section{CAP-induced antagonistic cytotoxicity of PtNPs on healthy cells}

Our results point to the potential of PtNP as a potent inhibitor of cytotoxicity. While this effect would not be desirable in treating cancer cells, the effect would be very beneficial to limit bystander damage if used to protect neighbouring healthy cells and tissues. To investigate whether the effect was also observed in healthy cells, the non-cancerous human embryonic kidney HEK293 cell line was used as contrast to U-251 MG cell line to measure cell viability. We treated non-cancerous cells with a range of concentrations of PtNPs combined with CAP to see effects of PtNPs on healthy cells. Our data indicated that HEK293 cell viability was approximately $60 \%$ after $50 \mathrm{sec}$ plasma treatment $24 \mathrm{~h}$ post-CAP treatment (Figure 5). Use of PtNPs at concentrations lower than $20 \mu \mathrm{g} / \mathrm{ml}$ did not lead to any measurable cytotoxicity in this cell line, however, at higher concentrations the PtNPs were cytotoxic and decreased cell viability.

We observed a similar protective effect when HEK293 cells were loaded with PtNP before exposure to CAP for the concentrations of PtNP ranged from $4 \mu \mathrm{g} / \mathrm{ml}$ to $0.256 \mathrm{ng} / \mathrm{ml}\left({ }^{* * P}<0.01, * * * \mathrm{P}<0.001\right.$ ) compared with CAP only. The $\mathrm{IC}_{50}$ value of PtNP alone is $8.782 \mu \mathrm{g} / \mathrm{ml}(95 \%$ confident intervals $=6.529$ $\mu \mathrm{g} / \mathrm{ml}$ to $11.81 \mu \mathrm{g} / \mathrm{ml}$ ) and the $\mathrm{IC}_{50}$ value of PtNP in combination with $50 \mathrm{~s}$ CAP treatment is $7.235 \mu \mathrm{g} / \mathrm{ml}$ ( $95 \%$ confident intervals $=5.366 \mu \mathrm{g} / \mathrm{ml}$ to $9.756 \mu \mathrm{g} / \mathrm{ml}$ ) (Supplementary Figure S1b). 


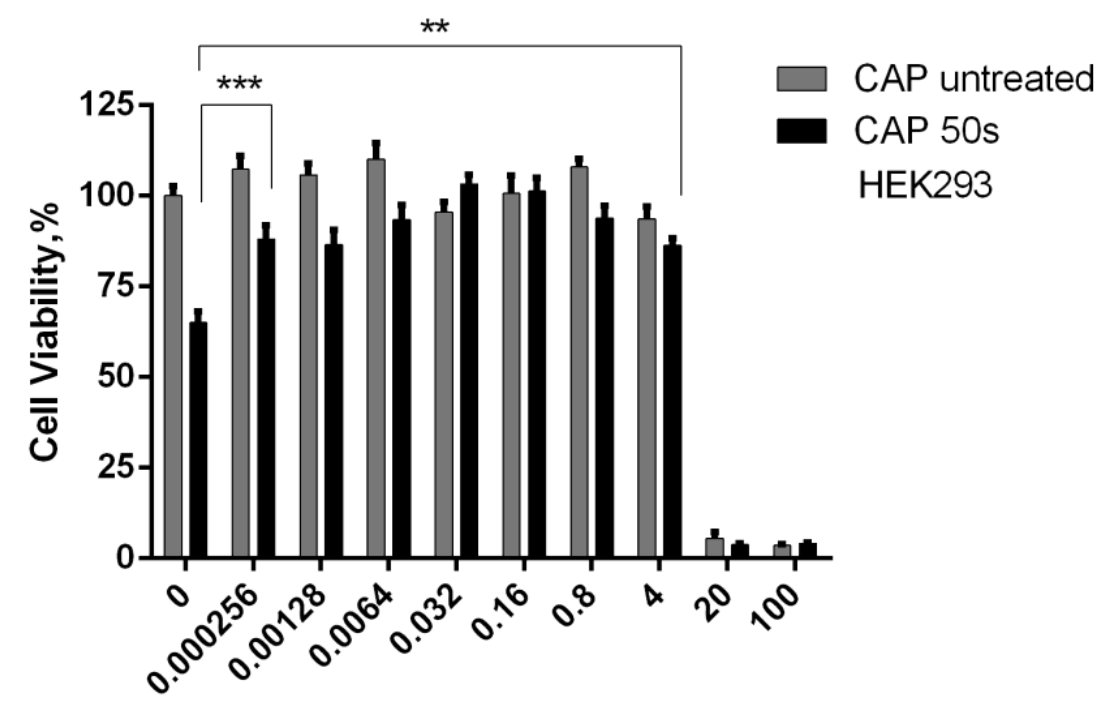

PtNPs concentration, $\mu \mathrm{g} / \mathrm{ml}$

Figure 5. Dose response curves for PtNPs treatment in non-cancerous cells. HEK293 cells were incubated with corresponding amounts of PtNPs for 24h before CAP treatment and Alamar blue analysis was carried out 24h after CAP treatment. Black bars represent the combination of CAP treatment and PtNPs. Grey bars represent no CAP treatment. The first bar depicts negative control and the second black bar shows CAP treatment only with no $0 \mu \mathrm{g} / \mathrm{ml}$ PtNPs.

\section{Discussion}

We have tested the PtNPs ( $3 \mathrm{~nm}$ ) both with U-251 MG cancer cell line (Figure 1A, B) and HEK293 noncancerous cell line (Figure 5) in combination with 50s CAP treatment. When the concentration of PtNP increased to $20 \mathrm{\mu g} / \mathrm{ml}$ and higher doses, cell viability rapidly decreased for both cell lines. We selected a dose of CAP close to the $\mathrm{IC}_{50}$ value in both cell lines, and as can be shown in figure $1 \mathrm{~A}$ and figure 5 , cytotoxicity measured was $50 \%$ and $40 \%$ for U-251 MG and HEK293 cells, respectively. Concentrations of PtNP at and below $4 \mu \mathrm{g} / \mathrm{ml}$ did not lead to significant cytotoxicity for both cell lines and our results are broadly consistent with other studies that indicate a low toxicity for PtNP29,30,38. We have observed similar $\mathrm{IC}_{50}$ values of PtNP alone and PtNP in combination with CAP treatment (Supplementary Figure S1a). Previous studies suggested that the size, shape, coating and surface area of noble-metal nanocrystals affect their catalytic properties ${ }^{39}$. For instance, Horie et al. (2011) treated A549 and HaCat cells with 5-10 
nm pure PtNPs up to $17.4 \mathrm{mg} / \mathrm{mL}$ and did not see any cytotoxic effects, oxidative stress or cell death ${ }^{29}$. Pedone et al. (2017) showed that 5 and $20 \mathrm{~nm}$ citrate-capped PtNPs up to $100 \mu \mathrm{g} / \mathrm{ml}$ was not harmful to HUVEC cells ${ }^{38}$. Manikadan et al. (2013) characterised size-dependent toxicity using a range of PtNPs sizes, stabilized with PVP from 1 to $21 \mathrm{~nm}$ in Neuro 2 cells for 12 hours and showed that all of the sizes resulted in cellular damage except for 5-6 nm (up to $50 \mu \mathrm{g} / 1 \times 10^{6}$ cells) ${ }^{40}$. Additionally, PVP-capped $5.8 \mathrm{~nm}$ PtNPs induced genotoxic effects and showed strong DNA damage at a concentration of $25 \mu \mathrm{g} / \mathrm{ml}$ but did not affect the cell viability at the time point of $24 \mathrm{~h}$ after PtNPs treatment in normal human epidermal keratinocytes ${ }^{41}$. Moreover, it was demonstrated that 1-5 nm PtNPs at concentrations up to $50 \mu \mathrm{g} / \mathrm{ml} \mathrm{did}$ not show cytotoxic effects in TIG-1, HeLa, HepG2, WI-38 and MRC-5 cells ${ }^{30}$. Studies demonstrate that the size of PtNPs is one of the main factors on insignificant cytotoxicity even at higher concentrations ${ }^{42,43}$. Some in vivo studies demonstrated that small size PtNPs $(2-19 \mathrm{~nm})$ did not cause any side effects on chicken embryogenesis and up to $20 \mu \mathrm{g} / \mathrm{ml}$ concentrations did not alter liver functionality ${ }^{44}$. 3-10 nm PVPPtNPs at concentrations up to $100 \mu \mathrm{g} / \mathrm{ml}$ did not show toxic effects on growth and development of zebrafish $^{45} .1 \mathrm{~nm}$ PtNPs treated mice did not show any toxicity profile in their heart, lungs, spleen and liver however they suffered nephrotoxicity. Additionally, in vitro data reported that $8 \mathrm{~nm}$ PtNPs showed great biocompatibility ${ }^{46}$. Although many studies focus on the antioxidant effect of PtNPs in vivo, it has been reported that $21 \mathrm{~nm}$ PtNPs can induce inflammatory responses ${ }^{47}$. We purchased $3 \mathrm{~nm}$ commercial PtNPs with fully characterized size, shape, coating, purity, concentration to aid our toxicological profiling and allow for standardization of results.

CAP generates oxygen-based species $(\cdot \mathrm{OH}),\left({ }^{1} \mathrm{O}_{2}\right),\left(\mathrm{O}_{2} \cdot{ }^{-}\right),\left(\mathrm{H}_{2} \mathrm{O}_{2}\right),\left(\mathrm{O}_{3}\right)^{48}$, as well as nitrogen-based species (NO), $\left(\mathrm{NO}_{2}\right),\left(\mathrm{NO}_{3}\right),\left(\mathrm{N}_{2} \mathrm{O}\right),\left(\mathrm{N}_{2} \mathrm{O}_{4}\right)^{48}$ in the gas phase. Physical elements include ultraviolet, heat, and electromagnetic fields in CAP. In addition to chemical and physical factors, positive charged ions such as $\mathrm{N}_{2}{ }^{+49}$ and electrons ${ }^{50}$ are also generated by CAP. The interaction of CAP-generated RONS and cells is an underlying principle for the anti-cancer effects of $\mathrm{CAP}^{51}$. Recently, many studies have focused on the 
potential selective killing effect of CAP in various cancer cells ${ }^{50,52}$. PtNP have previously been used for their antioxidant properties and it is proposed that PtNPs have a huge potential use as antioxidant nanodrugs ${ }^{53}$ by scavenging ROS in hepatic Kupffer cells ${ }^{54}$ or inhibiting apoptosis in human lymphoma U937 and $\mathrm{HH}$ cells ${ }^{55}$. Zheng et al. (2014) demonstrated that 2-4 nm PtNPs show synergistic scavenging activity with small antioxidant molecules ${ }^{53}$. PtNPs at low doses are capable of reducing ROS production caused by glucose, angiotensin and cholesterol treatments in endothelial cells ${ }^{53}$. Interestingly, Jawaid et al. (2016) reported that PtNPs show antagonism with Helium based CAP treatment. They demonstrated that PtNPs induced He-CAP desensitization in human lymphoma U937 cells and may inhibit pathways involved in apoptosis execution ${ }^{56}$. This study highlighted a very useful property of PtNP as possible catalase / SOD mimetics and their protective effect against CAP-induced cytotoxicity. It has been reported that PtNPs can catalyse the reduction of $\mathrm{H}_{2} \mathrm{O}_{2}$ to $\mathrm{H}_{2} \mathrm{O}$ and $\mathrm{O}_{2}$ by mimicking natural CAT. PtNPs are able to act as glutathione peroxidase, which launches the oxidation of a reduced substrate to decompose $\mathrm{H}_{2} \mathrm{O}_{2}$ to water, and they also catalyse the dismutation of $\mathrm{O}_{2}^{-}$into $\mathrm{O}_{2}$ and $\mathrm{H}_{2} \mathrm{O}_{2}$ as biological SOD mimics ${ }^{35,57}$. The potential of radical quenching ability of PtNPs, acting as enzyme mimetics, makes them promising candidates in cancer therapy and oxidative stress related diseases. However, it is not yet known whether this effect is observed in other CAP systems, or against adherent and non-cancerous cell lines.

We have investigated the potential antioxidant activity of PtNPs against ROS generated by DBD CAP system in U-251 MG and HEK293 cell lines. As Figure 2A presents, we detected significantly oxidised $\mathrm{H}_{2}$ DCFDA in the presence of $50 \mathrm{~s}$ CAP treatment. Previous studies show that the combination of CAP and nanoparticles together proposes a strong anticancer capacity by showing synergistic effects ${ }^{58}$. However, as Figure 2B demonstrates, PtNPs dramatically reduced the CAP-induced ROS production in cells with three different concentrations of PtNPs $(0.0512 \mathrm{ng} / \mathrm{ml}, 0.032 \mu \mathrm{g} / \mathrm{ml}$, and $5 \mu \mathrm{g} / \mathrm{ml})$ at concentrations that did not show any toxic effects in cells without CAP treatment. In addition, CAP-generated ROS levels were significantly decreased at a concentration of $0.032 \mu \mathrm{g} / \mathrm{ml}$ of PtNPs. 
We found that the fluorescence level of $\mathrm{H}_{2}$ DCFDA of CAP treated medium is not decreased by PtNPs in both increasing and/or decreasing (Figure 2C) concentrations of PtNPs, indicating the antioxidant effect of PtNP requires the nanoparticles either to be inside or near cells when exposed to CAP. One possibility is the mimetic activity of PtNP in cells. it has been reported that PtNPs act as a potent catalase mimetic at $\mathrm{pH} 7.4$ and a potent peroxidase mimetic at $\mathrm{pH} 4.5^{59}$. The $\mathrm{pH}$ value of culture medium is usually 7.4 , matching the $\mathrm{pH}$ of the cytosol and early endosomes. Other organelles such as late endosomes and lysosomes have much lower $\mathrm{pH}$ values, approaching 4.5 for lysosomes. Therefore, PtNP may act as either catalase or peroxidase mimetics in cells depending on their subcellular location. The localized accumulation of PtNPs in cellular compartments may drive localized antioxidant mimetic functions. Alternatively, PtNP may require the redox potential of living cells to fully catalyse redox reactions and quench reactive species ${ }^{59}$.

The PI staining measurements in Figure 3 show comparison of two different concentrations of PtNPs. PtNPs were not found to reduce the level of PI staining when compared with cells exposed only to $50 \mathrm{~s}$ CAP treatment. Our findings differ from Jawaid et al. (2016), who demonstrated using a He-CAP device that the PI staining was decreased in cells incubated with PtNPs during and after the CAP treatment, thus concluding that the fraction of secondary necrosis induced by 4 min He-CAP treatment was significantly decreased in the $300 \mu \mathrm{M}$ PtNP treated group compared to non-PtNPs group ${ }^{56}$. This difference may be due to the differences in experimental design and methods. Jawaid et al. (2016) synthesised PtNP using citrate reduction but did not characterise the size of PtNPs, incubated cells with PtNP immediately after CAP treatment, and used different cell lines and plasma devices to those used in the current study ${ }^{56}$. As is seen in Figure 3B, C, we have analysed the percentage of dead and viable cells following PI staining and report that preincubation of PtNPs do not reduce the percentage of dead cells (no significant difference when compared to CAP treatment). However, as is seen in Figure 1, 4 and 5 PtNPs were found to protect total cell viability against CAP induced cytotoxicity and protect mitochondria membrane potential against CAP- 
induced oxidative stress. Therefore, it may demonstrate that PtNPs cannot reduce the percentage of dead cells as a result of CAP treatment but can protect the remaining viable cells and may ease the oxidative stress induced by CAP treatment.

We have previously demonstrated that 60 s CAP treatment induced rapid cell membrane damage, which was still evident up to 120 hours after exposure, corresponding to a loss of cell viability ${ }^{36}$. In contrast, a lower doses of CAP (30 s) induced membrane oxidation and triggered plasma membrane recycling and repair, but did not cause any overall increase in membrane permeability or loss of cell viability ${ }^{12}$. The inference was that the membrane damage observed was a causative factor in the loss of cell viability. We have demonstrated here that CAP treatment induces cell membrane damage in U-251 MG cells. Interestingly, CAP-induced membrane permeabilisation was not reduced by PtNPs, but other downstream indicators of viability such as JC-1 and Alamar blue were improved. It is likely that the PtNPs were mainly accumulated inside cells and therefore did not protect against initial membrane damage but prevented downstream ROS-dependent cytotoxicity.

We have previously demonstrated that the cell membrane peroxidation is induced by CAP-generated extracellular ROS ${ }^{12}$. In the current study, we demonstrate that PtNPs in culture medium possess low antioxidant ability and do not protect against membrane permeabilisation induced by CAP treatment. The pre-incubation of PtNPs with U-251 MG cells allowed the accumulation of PtNPs in cells, which leads to a more potent antioxidant response in cells compared to the culture medium treatment only. This observation along with the decreased intracellular ROS observed in CAP-treated cells pre-incubated with PtNP led us to investigate the role of mitochondria in the protection against CAP-induced cytotoxicity.

CAP-induced ROS can cause oxidative stress, which targets mitochondria and results in mitochondrial dysfunction and cell death ${ }^{60}$, and is presented as the loss of the mitochondrial membrane potential $(\Delta \psi m)^{37}$. In agreement with these studies, we herein identified that CAP results in loss of mitochondrial 
membrane potential $24 \mathrm{~h}$ after the treatment in comparison with their untreated counterparts (Figure 4A and $4 \mathrm{~B})$ protected by low concentrations $(0.032 \mu \mathrm{g} / \mathrm{ml})$ of PtNP. Interestingly, high concentrations $(5$ $\mu \mathrm{g} / \mathrm{ml}$ ) of PtNP did not have a strong protective effect suggesting a possible disruption of normal cell function and viability occurs when using this higher dose of PtNP in conjunction with CAP.

In conclusion, we have demonstrated that, with intracellular accumulation, low doses of PtNPs showed non-to-low toxicity against U-251 MG and HEK293 cell lines while displaying significant protective effects against CAP induced cytotoxicity as a potent intracellular scavenger of ROS. With further investigation, PtNPs can be promising a candidate for cancer treatment by reducing the side effects of CAP therapy and other therapies that produce ROS by lowering intracellular ROS, preventing downstream cytotoxic signaling and providing cells time to repair the cellular damage caused by CAP.

\section{Acknowledgements}

This work is supported by TU DUBLIN Fiosraigh Research Scholarship programme (S.G., Z.H.), Science Foundation Ireland Grant Number 14/IA/2626 (P.C., J.C.).

\section{Author Contributions}

S.G., Z.H., R.M., P.C. and J.C. conceived the project and designed the experiments. S.G. and Z.H. performed the experiments, collected and analysed the data. S.G., Z.H., R.M., P.C., and J.C. co-wrote the paper. All authors discussed the results and reviewed the manuscript.

\section{Competing Interests}

The authors declare no competing interests. 


\section{Reference:}

1. Shi, X. M. et al. Effect of low-temperature plasma on deactivation of hepatitis B virus. IEEE Trans. Plasma Sci. 40, 2711-2716 (2012).

2. Mitra, A. et al. Applications in plasma medicine: A SWOT approach. Compos. Interfaces 19, 231-238 (2012).

3. Babington, P. et al. Use of cold atmospheric plasma in the treatment of cancer. Biointerphases vol. 10029403 (2015).

4. Kong, M. G., Keidar, M. \& Ostrikov, K. Plasmas meet nanoparticles-where synergies can advance the frontier of medicine. J. Phys. D. Appl. Phys. 44, 174018 (2011).

5. Schumacker, P. T. Reactive oxygen species in cancer cells: Live by the sword, die by the sword. Cancer Cell vol. 10 175-176 (2006).

6. Hersh, E. M. et al. Antiproliferative and antitumor activity of the 2-cyanoaziridine compound imexon on tumor cell lines and fresh tumor cells in vitro. J. Natl. Cancer Inst. (1992) doi:10.1093/jnci/84.16.1238.

7. Evens, A. M. et al. Motexafin gadolinium generates reactive oxygen species and induces apoptosis in sensitive and highly resistant multiple myeloma cells. Blood (2005) doi:10.1182/blood-2004-03-0964.

8. Gao, J., Liu, X. \& Rigas, B. Nitric oxide-donating aspirin induces apoptosis in human colon cancer cells through induction of oxidative stress. Proc. Natl. Acad. Sci. U. S. A. (2005) doi:10.1073/pnas.0506893102.

9. He, Z. et al. Cold Atmospheric Plasma Induces ATP-Dependent Endocytosis of Nanoparticles and Synergistic U373MG Cancer Cell Death. Sci. Rep. 8, 1-11 (2018).

10. Keidar, M., Yan, D. \& Sherman, J. H. Cold Plasma Cancer Therapy. Cold Plasma Cancer Therapy (2019). doi:10.1088/2053-2571/aafb9c.

11. Peng, X. \& Gandhi, V. ROS-activated anticancer prodrugs: A new strategy for tumor-specific damage. Ther. Deliv. 3, 823-833 (2012). 
12. He, Z. et al. Cold Atmospheric Plasma Stimulates Clathrin-Dependent Endocytosis to Repair Oxidised Membrane and Enhance Uptake of Nanomaterial in Glioblastoma Multiforme Cells. Sci. Rep. 10, (2020).

13. Manaloto, A. E. et al. Cold Atmospheric Plasma induces silver nanoparticle uptake, oxidative dissolution and enhanced cytotoxicity in Glioblastoma multiforme cells. bioRxiv (2020) doi:https://doi.org/10.1101/2020.02.28.969758.

14. Jalili, A., Irani, S. \& Mirfakhraie, R. Combination of cold atmospheric plasma and iron nanoparticles in breast cancer: Gene expression and apoptosis study. Onco. Targets. Ther. (2016) doi:10.2147/OTT.S95644.

15. Li, W. et al. Cold atmospheric plasma and iron oxide-based magnetic nanoparticles for synergetic lung cancer therapy. Free Radic. Biol. Med. (2019) doi:10.1016/j.freeradbiomed.2018.10.429.

16. Sohmiya, M., Tanaka, M., Okamoto, K., Fujisawa, A. \& Yamamoto, Y. Synergistic inhibition of lipid peroxidation by vitamin $\mathrm{E}$ and a dopamine agonist, cabergoline. Neurol. Res. (2004) doi:10.1179/016164104225016029.

17. Weyant, M. J., Carothers, A. M., Dannenberg, A. J. \& Bertagnolli, M. M. (+)-catechin inhibits intestinal tumor formation and suppresses focal adhesion kinase activation in the Min/+ mouse. Cancer Res. 61, 118-125 (2001).

18. Nitta, Y. et al. Induction of Transplantable Tumors by Repeated Subcutaneous Injections of Natural and Synthetic Vitamin E in Mice and Rats. Japanese J. Cancer Res. (1991) doi:10.1111/j.13497006.1991.tb01880.x.

19. Omenn, G. S. et al. Risk factors for lung cancer and for intervention effects in CARET, the beta-carotene and retinol efficacy trial. J. Natl. Cancer Inst. (1996) doi:10.1093/jnci/88.21.1550.

20. Mazza, J., Rossi, A. \& Weinberg, J. M. Innovative uses of tumor necrosis factor $\alpha$ inhibitors. Dermatologic Clinics vol. 28 559-575 (2010).

21. Jee, J. P. et al. Cancer targeting strategies in nanomedicine: Design and application of chitosan nanoparticles. Current Opinion in Solid State and Materials Science (2012) doi:10.1016/j.cossms.2013.01.002. 
22. Yoshihisa, Y. et al. Protective effects of platinum nanoparticles against UV-light-induced epidermal inflammation. Exp. Dermatol. (2010) doi:10.1111/j.1600-0625.2010.01128.x.

23. Onizawa, S., Aoshiba, K., Kajita, M., Miyamoto, Y. \& Nagai, A. Platinum nanoparticle antioxidants inhibit pulmonary inflammation in mice exposed to cigarette smoke. Pulm. Pharmacol. Ther. (2009) doi:10.1016/j.pupt.2008.12.015.

24. McKee, D. W. Catalytic decomposition of hydrogen peroxide by metals and alloys of the platinum group. J. Catal. (1969) doi:10.1016/0021-9517(69)90326-1.

25. Bianchi, G., Mazza, F. \& Mussini, T. Catalytic decomposition of acid hydrogen peroxide solutions on platinum, iridium, palladium and gold surfaces. Electrochim. Acta (1962) doi:10.1016/0013-4686(62)80034-6.

26. Kajita, M. et al. Platinum nanoparticle is a useful scavenger of superoxide anion and hydrogen peroxide. Free Radic. Res. (2007) doi:10.1080/10715760601169679.

27. Kawanishi, S., Oikawa, S. \& Murata, M. Evaluation for safety of antioxidant chemopreventive agents. Antioxidants and Redox Signaling (2005) doi:10.1089/ars.2005.7.1728.

28. Hirakawa, K., Oikawa, S., Hiraku, Y., Hirosawa, I. \& Kawanishi, S. Catechol and hydroquinone have different redox properties responsible for their differential DNA-damaging ability. Chem. Res. Toxicol. (2002) doi:10.1021/tx010121s.

29. Horie, M. et al. Evaluation of cellular influences of platinum nanoparticles by stable medium dispersion. Metallomics (2011) doi:10.1039/c1mt00060h.

30. Hamasaki, T. et al. Kinetic analysis of superoxide anion radical-scavenging and hydroxyl radical-scavenging activities of platinum nanoparticles. Langmuir (2008) doi:10.1021/la704046f.

31. Ayaz Ahmed, K. B., Raman, T. \& Anbazhagan, V. Platinum nanoparticles inhibit bacteria proliferation and rescue zebrafish from bacterial infection. RSC Adv. (2016) doi:10.1039/c6ra03732a.

32. Kim, J. et al. Effects of a potent antioxidant, platinum nanoparticle, on the lifespan of Caenorhabditis elegans. 
Mech. Ageing Dev. (2008) doi:10.1016/j.mad.2008.02.011.

33. Watanabe, A. et al. In vitro free radical scavenging activity of platinum nanoparticles. Nanotechnology (2009) doi:10.1088/0957-4484/20/45/455105.

34. Clark, A., Zhu, A., Sun, K. \& Petty, H. R. Cerium oxide and platinum nanoparticles protect cells from oxidantmediated apoptosis. J. Nanoparticle Res. (2011) doi:10.1007/s11051-011-0544-3.

35. Zhang, L. et al. Reducing stress on cells with apoferritin-encapsulated platinum nanoparticles. Nano Lett. (2010) doi:10.1021/nl903313r.

36. Conway, G. E. et al. Cold Atmospheric Plasma induces accumulation of lysosomes and caspase-independent cell death in U373MG glioblastoma multiforme cells. Sci. Rep. 9, 1-12 (2019).

37. Ahn, H. J. et al. Atmospheric-pressure plasma jet induces apoptosis involving mitochondria via generation of free radicals. PLoS One 6, 6-12 (2011).

38. Pedone, D., Moglianetti, M., De Luca, E., Bardi, G. \& Pompa, P. P. Platinum nanoparticles in nanobiomedicine. Chem. Soc. Rev. 46, 4951-4975 (2017).

39. Burda, C., Chen, X., Narayanan, R. \& El-Sayed, M. A. Chemistry and properties of nanocrystals of different shapes. Chemical Reviews (2005) doi:10.1021/cr030063a.

40. Manikandan, M., Hasan, N. \& Wu, H. F. Platinum nanoparticles for the photothermal treatment of Neuro 2A cancer cells. Biomaterials (2013) doi:10.1016/j.biomaterials.2013.03.077.

41. Konieczny, P. et al. Effects triggered by platinum nanoparticles on primary keratinocytes. Int. J. Nanomedicine (2013) doi:10.2147/IJN.S49612.

42. Gehrke, H. et al. Platinum nanoparticles and their cellular uptake and DNA platination at non-cytotoxic concentrations. Arch. Toxicol. 85, 799-812 (2011).

43. Rehman, M. U., Yoshihisa, Y., Miyamoto, Y. \& Shimizu, T. The anti-inflammatory effects of platinum nanoparticles on the lipopolysaccharide-induced inflammatory response in RAW 264.7 macrophages. 
Inflamm. Res. (2012) doi:10.1007/s00011-012-0512-0.

44. Prasek, M. et al. Influence of nanoparticles of platinum on chicken embryo development and brain morphology. Nanoscale Res. Lett. (2013) doi:10.1186/1556-276X-8-251.

45. Asharani, P. V., Lianwu, Y., Gong, Z. \& Valiyaveettil, S. Comparison of the toxicity of silver, gold and platinum nanoparticles in developing zebrafish embryos. Nanotoxicology (2011) doi:10.3109/17435390.2010.489207.

46. Yamagishi, Y. et al. Acute and chronic nephrotoxicity of platinum nanoparticles in mice. Nanoscale Res. Lett. (2013) doi:10.1186/1556-276X-8-395.

47. Park, E. J. et al. Inflammatory responses may be induced by a single intratracheal instillation of iron nanoparticles in mice. Toxicology (2010) doi:10.1016/j.tox.2010.06.002.

48. Thiyagarajan, M., Anderson, H. \& Gonzales, X. F. Induction of apoptosis in human myeloid leukemia cells by remote exposure of resistive barrier cold plasma. Biotechnol. Bioeng. (2014) doi:10.1002/bit.25114.

49. Ja Kim, S., Min Joh, H. \& Chung, T. H. Production of intracellular reactive oxygen species and change of cell viability induced by atmospheric pressure plasma in normal and cancer cells. Appl. Phys. Lett. 103, (2013).

50. Kalghatgi, S. et al. Effects of non-thermal plasma on mammalian cells. PLoS One 6, 1-11 (2011).

51. Graves, D. B. The emerging role of reactive oxygen and nitrogen species in redox biology and some implications for plasma applications to medicine and biology. Journal of Physics D: Applied Physics vol. 45 (2012).

52. Thiyagarajan, M., Waldbeser, L. \& Whitmill, A. THP-1 leukemia cancer treatment using a portable plasma device. in Studies in Health Technology and Informatics (2012). doi:10.3233/978-1-61499-022-2-515.

53. Zheng, W. et al. Screening reactive oxygen species scavenging properties of platinum nanoparticles on a microfluidic chip. Biofabrication (2014) doi:10.1088/1758-5082/6/4/045004.

54. Katsumi, H. et al. Pharmacokinetics and preventive effects of platinum nanoparticles as reactive oxygen species scavengers on hepatic ischemia/reperfusion injury in mice. Metallomics (2014) 
doi:10.1039/c4mt00018h.

55. Yoshihisa, Y. et al. SOD/catalase mimetic platinum nanoparticles inhibit heat-induced apoptosis in human lymphoma U937 and HH cells. Free Radic. Res. (2011) doi:10.3109/10715762.2010.532494.

56. Jawaid, P. et al. Helium-based cold atmospheric plasma-induced reactive oxygen species-mediated apoptotic pathway attenuated by platinum nanoparticles. J. Cell. Mol. Med. 20, 1737-1748 (2016).

57. Moglianetti, M. et al. Platinum nanozymes recover cellular ROS homeostasis in an oxidative stress-mediated disease model. Nanoscale (2016) doi:10.1039/c5nr08358c.

58. Yan, D., Nourmohammadi, N., Talbot, A., Sherman, J. H. \& Keidar, M. The strong anti-glioblastoma capacity of the plasma-stimulated lysine-rich medium. J. Phys. D. Appl. Phys. (2016) doi:10.1088/0022$3727 / 49 / 27 / 274001$.

59. Li, J., Liu, W., Wu, X. \& Gao, X. Mechanism of pH-switchable peroxidase and catalase-like activities of gold, silver, platinum and palladium. Biomaterials (2015) doi:10.1016/j.biomaterials.2015.01.012.

60. Lee, J., Giordano, S. \& Zhang, J. Autophagy, mitochondria and oxidative stress: Cross-talk and redox signalling. Biochemical Journal (2012) doi:10.1042/BJ20111451. 